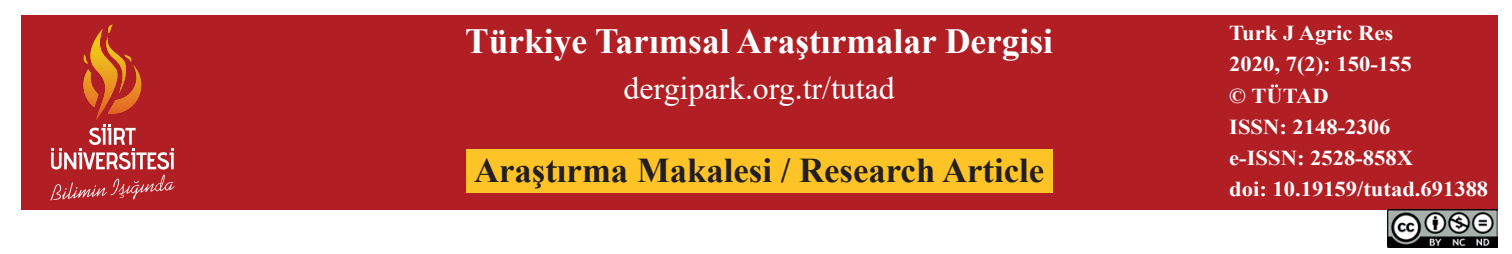

\title{
Fındık Yetiştiriciliği Yapan İşletmelerde Kadınların İşgücüne Katılımı ve İşletme Kararlarına Etkisi: Samsun İli Örneği, Türkiye
}

\author{
Osman KILIÇ ${ }^{*}$, Gamze AYDIN ERYILMAZ ${ }^{2}$, İsmet BOZ ${ }^{1}$ \\ ${ }^{1}$ Ondokuz Mayls Üniversitesi, Ziraat Fakültesi, Tarım Ekonomisi Bölümü, Samsun, TÜRKIYYE \\ ${ }^{2}$ Ondokuz Mayıs Üniversitesi, Samsun Meslek Yüksekokulu, Park ve Bahçe Bitkileri Bölümü, Samsun, TÜRKIYYE
}

Geliş Tarihi/Received: 19.02 .2020

Kabul Tarihi/Accepted: 18.06 .2020

\begin{tabular}{l}
\hline ORCID ID (Yazar surasma göre / by author order) \\
(1Dorcid.org/0000-0002-0129-4034 (Dorcid.org/0000-0002-4440-8687 (1Dorcid.org/0000-0001-7316-9323 \\
"Sorumlu Yazar/Corresponding Author: okilic@omu.edu.tr
\end{tabular}

Öz: Araştırmanın amacı, fındık yetiştiriciliği yapan işletmelerde kadınların işgücüne katılımını ve işletmeyle ilgili teknik ve ekonomik konulardaki kararlara etkisini ortaya koymaktır. Veriler, Türkiye'nin Orta Karadeniz Bölgesi'nde yer alan Samsun ili Çarşamba ve Terme ilçelerinde fındık yetiştiriciliği yapan 72 işletmeyle, 2019 yılında yapılan anketlerden elde edilmiştir. İncelenen işletmelerde, ortalama 33.67 dekar olan işletme arazisinin \% 55.90’1 findık arazisine aittir. İşletmelerde findığın tercih edilmesinin en önemli nedeni olarak, \% 73.61 ile findığın alternatif ürünlere göre daha kârlı olmas1 gösterilmiştir. Diğer önemli nedenler ise, fındığa alım garantisinin verilmesi (\% 54.70) ve findığın uzun süre depolanabilir olmasıdır (\% 47.22). İșletmelerde aile nüfusu ortalama 4.57 kiși olup, bunun \% 52.95'i kadınlardan oluşmaktadır. İşletmelerde kadınlar, findık hasadı başta olmak üzere tarımsal işlerin tamamında çalışmaktadır. Kadınlar, tarımsal faaliyetler için kullanılan işgücünün \% 50.91'ini eșiyle, \% 21.82'sini kendisi, \% 14.55'ini çocuklarıyla, geriye kalan \% 12.72'sini eltisi, gelini, kayınpederi ve kayınvalidesiyle birlikte yapmaktadır. İşletmelerde kadınlar daha çok yetiştirilecek ürünün belirlenmesi, gübre kullanımı ve hayvan satışıla ilgili kararlarda etkilidir. Fındık yetiştiriciliğinde kullanılan işgücünün \% 36.70'i kadın işgücü olmasına rağmen, kredi kullanımı, pazarlama ve tarımsal eğitimle ilgili kararlarda kadınların etkisi oldukça düşüktür. Kadınların aile içindeki etkisinin artırılması ve işletme kararlarına daha fazla katılımlarının sağlanmasında, kadınları bilinçlendirmeye yönelik projelerin yapılması önemlidir. Bu sayede kırsal alandaki kadınların, toplumun kendilerine atfettiği rolleri kabullenmek yerine, sosyal hayatta olduğu gibi işletmeyle ilgili ekonomik kararlarda da aktif olarak yer almaları sağlanmış olacaktır.

Anahtar Kelimeler: Fındık, kadın işgücü, tarım işletmesi, işletme kararları, kırsal alan

\section{Women Labor Force Participation and Impact on Business Decisions in Hazelnut Production Enterprises: The Case Study of Samsun Province, Turkey}

Abstract: This study aimed to investigate the participation of women in labor on hazelnut farms and their involvement in technical and economical decisions about the farm. The data were collected from 72 farms engaged in hazelnut cultivation in Çarşamba and Terme districts of Samsun province located in the Central Black Sea Region of Turkey in 2019. The average farm area was 33.67 decares, of which $55.90 \%$ was devoted to hazelnut growing. The most important reason for farmers to prefer hazelnut in their farms was that it was more profitable than alternative products with $73.61 \%$. Other important reasons were the guarantee of purchase $(54.70 \%)$, and the ease of long-term storage $(47.22 \%)$. The average number of family members on the farms was 4.57 , of which $52.95 \%$ were females. Women engaged in most agricultural activities, especially in hazelnut harvesting. Women carry out $50.91 \%$ of the labor activities with their spouses, $21.82 \%$ by themselves, $14.55 \%$ with their children, and $12.72 \%$ with their sisters in law, fathers-in-law or mothers-in-law. The women in farms are more effective in decisions such as; products to be grown, the use of fertilizers, and the sale of livestock. Although $36.70 \%$ of the 
labor of hazelnut cultivation is female labor, the involvement of women in credit use, marketing, and agricultural education activities is quite low. It is important to carry out projects aimed at raising womens' awareness to increase their influence in the family and to promote greater participation in the process of making farm decisions. In this way, instead of accepting the roles that the society attributes to them, rural women will be actively involved in economic decisions related to the business as well as in social life.

Keywords: Hazelnut, woman labor, farm, farm decisions, rural area

\section{Giriş}

Ekonomik kalkınmanın gerçekleştirilebilmesi, üretim faktörlerinin etkin ve dengeli kullanılmasına bağlıdır. Üretim faktörleri arasındaki tek aktif unsur emek olup, diğer üretim faktörlerinin kullanımı işgücü ve müteşebbis tarafından sağlanmaktadır. İşgücü ve müteşebbisin aktif olma özellikleri, onları en önemli üretim faktörleri haline getirmektedir. Bir ülkenin kaynakları ne kadar zengin olursa olsun, onları kullanacak işgücü yoksa veya yetersizse ekonomik kalkınmanın gerçekleştirilmesi mümkün değildir (Cinemre ve Kılıç, 2015). Bu bakımdan tarımsal üretimin her aşamasında etkili olan kadınların güçlendirilmesine yönelik uygulamalarda, kadının kalkınma sürecine katılımının sağlanması ve birey olarak güçlü yönlerinin ortaya çıkarılması önemlidir.

Tarım sektöründe yaşayan kadınların işgücüne katılma biçimleri, ülkenin ekonomik ve kültürel yapısıyla yakından ilgilidir. Kadın işgücü gelişmekte olan ülkelerde tarım sektöründe yoğunlaşırken, gelişmiş ülkelerde daha çok hizmet sektöründe yer almaktadır. Buna bağlı olarak, gelişmiş ülkelerde ücretsiz aile işçiliğinin yerini ücretli kadın emeği almaktadır (Berber ve Eser, 2008). Kadının toplumdaki yeri ülkelerin gelişmişlik düzeylerine göre farklılık göstermesine rağmen, tüm dünya ülkelerinde işgücünün kullanımı açısından erkeklerin lehine bir dağılım söz konusudur (Özer ve Biçerli, 2003). Çalışma hayatının her alanında bulunan kadınlar, dünyada yoksulluktan en fazla etkilenen ve büyük ölçüde ücretsiz aile işçisi konumundadır. Türkiye' de ise kırsal ve kentsel alanda aktif olarak yer alan kadınların, ev işleriyle ilgili sorumlulukları her zaman ön planda olmaktadır.

Türkiye'de kentsel alandaki kadınlar çoğunlukla kapalı ortamda, ücretli işgücü olarak daha iyi şartlarda çalışırken, kırsal alandaki kadınlar genellikle açık alanda, ücretsiz aile işgücü olarak daha ağır işlerde çalışmaktadır. Oysaki kırsal alandaki kadınlar, ailenin sosyal ve ekonomik yapısı içinde erkeklerle aynı oranda ve hatta çoğu iște erkeklerden daha fazla sorumluluk taşımaktadır. Türkiye genelinde 2018 yılı itibariyle 15 yaş ve üzerindeki çalışan nüfusun \% 68.78'ini erkek, \% 31.22'sini kadınlar oluşturmaktadır.
Kirsal alanda istihdam edilen nüfusun ise \% 57.38'i erkek, \% 42.62'si kadındır (Anonim, 2018). Bu sonuç, kırsal alandaki kadın istihdamı oranının Türkiye geneline göre daha yüksek olduğunu göstermektedir.

Kırsal alandaki ataerkil yapının, kadınların erkeklerle eşit söz hakkına sahip olmasını zorlaştırdığı, bu yüzden kadınların daha çok emekleriyle var oldukları söylenebilir. Kırsal alandaki kadınların tarımsal faaliyetlere katılımı, genellikle erkekler için yardımcı işgücü statüsünde değerlendirilmektedir. Türkiye'nin değişik bölgelerinde yapılan araştırmalara göre, kırsal alandaki kadınlar işgücü yönünden önemli rol üstlenmelerine rağmen, işletmeyle ilgili karar süreçlerinde erkeklerin gerisinde kalmaktadır (Bayoğlu, 2010; Kaya ve Atsan, 2012; Kutlar ve ark., 2013; Alkan, 2015; Y1lmaz ve ark., 2019). Türkiye'de kırsal alanda yaşayan kadınların, işletmedeki kararlara katılımı ve kendi adına bir tarım işletmesine sahip olması gibi kadını daha güçlü kılan olanakların yetersiz olmasının birçok sosyolojik ve kültürel nedeni bulunmaktadır. Bunlardan en önemlisi kırsal toplumun kadına biçmiş olduğu rol olup, bu rolü üstlenebilmek için kadının genç yaşta evlenmesi, yuva kurması, çocuk sahibi olması, eşine yardım etmesi ve ev işlerinin dışında tarımsal faaliyetlere işgücü olarak katkıda bulunması gerekmektedir (Palaz ve Boz, 2007).

Türkiye'de fındık yetiştiriciliği, tarım işletmeleri açısından önemli bir gelir kaynağ olmasının yanı sıra, sektör olarak önemli bir istihdam kaynağı durumundadır. Türkiye'de doğrudan ve dolaylı olmak üzere yaklaşık 4 milyon kişiye istihdam sağlayan fındık sektörü (Anonymous, 2014), ekonomik açıdan olduğu kadar sosyal açıdan da stratejik bir öneme sahiptir. Türkiye'de fındık yetiştiriciliği 36 ilde yapılmasına rağmen, üretim miktarı 6 ilde (Ordu, Sakarya, Samsun, Giresun, Düzce, Trabzon) yoğunlaşmaktadır. Samsun ili, 4 yılın ortalamasına göre (2016-2019) yıllık 596.5 bin ton olan Türkiye findik üretiminin yaklaşık \% 15'ini (Anonim, 2019) karşılayan önemli fındık üretim merkezlerinden biri konumundadır. Samsun ilindeki fındık üretiminin büyük bir kısmı, Çarşamba ve Terme ilçelerinin ova köylerindeki bahçelerden elde edilmektedir. 
Türkiye'de kırsal alanda kadın işgücüne bakış ve kadınların konumuna ilişkin genel yargılar bölgeye, işletmenin yapısına ve üretilen ürünlere göre değişmektedir. Fındık yetiştiriciliği, kadın işgücü kullanımının fazla olduğu tarımsal üretim faaliyetlerinden birisidir. $\mathrm{Bu}$ bağlamda findik işletmelerinde; kadın işgücünün çalışma şartlarının iyileştirilmesi, kadınların nitelik olarak geliştirilmesi, girişimcilik kapasitelerinin artırılması ve daha fazla organize olmalarını sağlayacak örgütlenme modellerinin planlanması gibi konular ön plana çıkmaktadır. Bu araştırmada, Çarşamba ve Terme ilçelerinin ova köylerinde fındık yetiştiriciliği yapan işletmelerdeki kadınlara ait sosyo-ekonomik özellikler, yapılan işlemlere göre kadın işgücü kullanımı ve kadınların işletmeyle ilgili kararlara etkisi ortaya konulmuştur.

\section{Materyal ve Yöntem}

Araştırmanın materyalini, Samsun ili Çarşamba ve Terme ilçelerinin ova köylerinde findik yetiştiriciliği yapan işletmelerle yapılan anketler oluşturmaktadır. Araştırmada, örnekleme birimi olarak işletme arazisi büyüklüğü esas alınmıştır. Anket sayısının belirlenmesinde, tabakalı tesadüfi örnekleme yöntemi kullanılmıştır (Yamane, 1967). Buna göre, anket yapılan işletme sayısı 72 olarak tespit edilmiştir. Anketler, 2019 yılının Kasım ve Aralık aylarında yapılmıştır.

Fındık işletmelerinde tarımsal üretim ve işletmenin genel idaresiyle ilgili kararlar, işletme sahibi konumundaki erkekler ile eş ya da ailedeki diğer bir kadın tarafindan alınmaktadır. $\mathrm{Bu}$ bakımdan işletmelerin genel özelliklerine ait veriler erkeklerden, kadınlarla ilgili veriler ise eş, kayınvalide ya da gelin konumundaki kadınlardan elde edilmiştir. Anketlerde; erkeklerden kendilerine ait sosyo-ekonomik özellikler ile aile nüfusu, arazi yapısı, fındık arazisine ait özellikler, fındık yetiştiriciliğinde işgücü kullanımı ve fındık yetiştiriciliğinin tercih edilme nedenleriyle ilgili bilgiler alınmıştır. Kadınlardan ise kadınlara ait sosyo-ekonomik özellikler ile işletmedeki üretim faaliyetleriyle ilgili kararlarda kadınların etkisine yönelik veriler elde edilmiştir.

Fındık yetiştiriciliğinde yapılan işlemler için kullanılan işgücü miktarları, erkek işgücü saati (EİGS) cinsinden hesaplanmıştır. Çalışan nüfusun erkek işgücü birimine çevrilmesinde; 7-14 yaş grubundaki erkek ve kadınlar için 0.50, 15-64 yaş grubundaki erkekler için 1, kadınlar için 0.75, 64 yaşından büyük erkekler için 0.75, kadınlar için 0.50 alınmıştır (Erkuş ve Demirci, 1985). Fındık yetiştiriciliği için günlük çalışma süresi 9 saat kabul edilmiştir. Araştırmada anketlerden elde edilen veriler, işletmeler ortalamasına göre analiz edilmiştir.

\section{Bulgular ve Tartışma}

İncelenen işletmelerde ortalama 4.57 kişi olan aile nüfusunun \% 52.95'i kadınlardan oluşmaktadır. İşletme arazisi büyüklüğü ortalama 33.67 dekar olup, arazinin \% 55.90’1 findık, \% 44.10’u diğer ürünlere (çeltik, mısır, sebze, findık dişındaki diğer meyveler) aittir. İşletme arazisinin \% 93.91'i mülk araziden oluşmaktadır. İşletmelerde kiracılık ve ortakçılık, fındık dışındaki diğer ürünlerde söz konusudur. İşletmelerin \% 70.83'ü bitkisel üretimle birlikte hayvancılığa yer verirken, \% 29.17'si sadece bitkisel üretim yapmaktadır. İşletmelerde üretilen findığın tamamına yakını satılırken, çok azı evde tüketilmek için ayrılmaktadır. Araştırma alanındaki fındık bahçelerinin yaşı ortalama 38.36 yıl olup, bahçelerin \% 66'sı karışık, \% 34'ü ise tek çeşitten oluşmaktadır (Tablo 1). Fındık işletmelerinde esas gelirin findıktan elde edildiği ve işletmelerin büyük ölçüde findığa bağımlı oldukları söylenebilir. Ayrıca pazara sunulan ve işletmelere doğrudan nakit girdisi sağlayan ürünler açısından bakıldığında, fındığın işletmeler açısından önemi daha fazla olmaktadır.

Tablo 1. İşletmelere ait özellikler

\begin{tabular}{lc}
\hline & Ortalama \\
\hline Aile nüfusu (kişi) & 4.57 \\
\hline Ailedeki kadın sayısı (kişi) & 2.42 \\
\hline İşletme arazisi (da) & 33.67 \\
\hline Mülk (da) & 31.62 \\
Kiralık (da) & 2.55 \\
Kiraya ve ortağa verilen (da) & 0.50 \\
Fındık (da) & 18.82 \\
Diğer ürünler (da) & 14.85 \\
\hline Fındık bahçesinin yaşı (yıl) & 38.36 \\
\hline Fındık çeşidi (\%) & 66.00 \\
\hline Karışı & 34.00 \\
\hline Tek çeşit & 29.17 \\
\hline Bitkisel üretim yapanlar (\%) & 70.83 \\
\hline Bitkisel+hayvancılık yapanlar (\%) & 2.50 \\
\hline Büyükbaş hayvan sayısı (baş) & 0.82 \\
\hline Küçükbaş hayvan sayısı (baş)
\end{tabular}

İncelenen işletmelerde anket yapılan erkeklerin yaşı ortalama 53.05 yıl, kadınların ise 49.75 yıldır. Erkeklerin eğitim gördükleri süre $(9.28$ yıl), kadınlardan (5.80 yıl) \% 60.00 daha fazladır. Fındık yetiştiriciliğiyle ilgili deneyim erkeklerde 32.59 y1l, kadınlarda ise 27.35 yıldır. Anket yapılan kadınların \% 89.50 'si eş, \% 7.00 '1 kayınvalide ve \% 3.50'si gelindir. Kadınların $\%$ 56.10’u görücü usulüyle evlilik yaparken, ailenin rızası olmadan evlilik yapanların oranı $\%$ 7.00'dır. Eşiyle anlaşarak evlenenlerin oranı ise 
\% 36.90'dır. Eşiyle akrabalığı olmayan kadınların oranı \% 80.70 iken, \% 19.30'u akraba evliliği yapmiştır (Tablo 2). Türkiye'de son yillarda görücü usulüyle yapılan evliliklerde önemli oranda azalma olsa da, kirsal alanda geleneklere bağlılığını sürdüren sosyal yap1 nedeniyle anlaşmalı evlilik oranı hâlen düşük düzeydedir. Ankara, İstanbul ve Edirne illerinin kirsal alanlarında yapılan bir araştırmada, kadınların \% 44.8'inin anlaşmalı, \% 55.2'sinin görücü usulüyle evlendikleri tespit edilmiştir (Kaya, 2017). Aynı şekilde Şanlıurfa ilinin kırsal alanında yapılan başka bir araştırmada da, görücü usulüyle yapılan evliliğin (\% 67.3) yaygın olduğu ortaya konulmuştur (Yılmaz ve Ersin, 2019).

Tablo 2. Erkek ve kadınlara ait sosyo-ekonomik özellikler

\begin{tabular}{lr}
\hline & Ortalama \\
\hline Erkeğe ait özellikler & \\
\hline Yaş (yıl) & 53.05 \\
Eğitim süresi (yıl) & 9.28 \\
Tarımsal deneyim (yıl) & 35.82 \\
Fındık yetiştiriciliğindeki deneyim (yıl) & 32.59 \\
\hline Kadına ait özellikler & \\
\hline Yaş (yıl) & 49.75 \\
Eğitim süresi (yıl) & 5.80 \\
Tarımsal deneyim (yıl) & 32.29 \\
Fındı yetiştiriciliğindeki deneyim (yıl) & 27.35 \\
\hline Ailedeki rolü (\%) & \\
\hline Evin hanımı & 89.50 \\
Kayın valide & 7.00 \\
Gelin & 3.50 \\
\hline Medeni durumu (\%) \\
\hline Evli \\
Dul \\
\hline Evlilik şekli (\%) \\
\hline Görücü & 98.20 \\
Anlaşmalı & 1.80 \\
\hline Aile rızası olmadan & 56.10 \\
\hline Eşiyle akrabalık durumu (\%) & 36.90 \\
\hline Akraba & 7.00 \\
\hline Akraba değil & 19.30 \\
\hline
\end{tabular}

Türkiye'de findık, 1962 yılından itibaren Fiskobirlik aracılığıyla devlet tarafından alım garantisi verilen bir ürün olmuştur. Son yıllarda ise Fiskobirlik kendi adına fındık alımı yaparken, Toprak Mahsulleri Ofisi aracılığıyla taban fiyatı yoluyla fındık alımı devam etmektedir. İncelenen işletmelerde fındık yetiştiriciliği yapılmasının en önemli nedeni olarak, \% 73.61 ile findığın alternatif ürünlere göre daha kârlı olması gösterilmiştir. Bunu sırasıyla \% 54.70 ile findığa alım garantisi verilmesi, \% 47.22 ile findığın uzun süre depolanabilir olması, \% 40.28 ile findığa alternatif ürün olmaması, \% 35.80 ile findığın daha az işgücü gerektirmesi ve \% 24.61 ile işletmedeki aile işgücünün yetersizliği izlemektedir.
Anket yapılan kadınların tamamı tarımla ilgili işlerde çalışmaktadır. Bitkisel ve hayvansal üretim faaliyetlerinde kullanılan işgücünün \% 50.91'i kadınların eşleriyle birlikte yaptıkları işlerden oluşurken, \% 21.82'si kadınların tek başlarına yaptıkları işlere aittir. Aynı zamanda kadınlar; çocuğu (\% 14.55), eltisi (\% 5.45), gelini (\% 5.45), kayınpederi ve kayınvalidesiyle de (\% 1.82) görev paylaşımı yapmaktadır. Erzurum, Erzincan ve Bayburt'u kapsayan üç ilde yapılan bir araştırmada, kadınların sebze üretimiyle ilgili işleri tek başlarına veya evdeki diğer kadınlarla birlikte yaptıkları tespit edilmiştir (Kaya ve Atsan, 2012).

Fındık yetiştiriciliğinde işgücünün \% 41.95 gibi önemli bir kısmı hasatta kullanılmaktadır. Bunu; sırasıyla \% 16.61 ile dip sürgünü temizliği, $\% 15.90$ ile yabancı ot temizliği, \% 13.13 ile budama, \% 4.35 ile gübreleme, $\% 3.67$ ile ilaçlama, \% 3.17 ile taşıma ve \% 1.22 ile patoza verme takip etmektedir. Findık yetiştiriciliğinde erkek işgücü saati cinsinden dekara kullanılan toplam işgücünün (57.49 EİGS da ${ }^{-1}$ ) \% 63.30’u erkeklere, \% 36.70'i kadınlara aittir. İşletmelerde kullanılan kadın işgücü oranı \% 62.11 ile hasat işleminde yüksek iken, diğerlerinde erkek işgücü oranı daha yüksektir (Tablo 3). Tokat ilinde yapılan bir araştırmaya göre kadınlar, bitkisel üretim faaliyetlerinde en fazla çapalama (\% 90.06), yabanc1 ot temizliği (\% 74.85) ve hasatta (\% 67.84) çalışmaktadır (Kızılaslan ve Yamanoğlu, 2010). Tekirdağ ilinde yapılan bir araştırmada ise, kadınların bitkisel üretimde en fazla ( $\%$ 78.4) çapalama ve ekim ( $\left.\begin{array}{lll}\% & 64.3\end{array}\right)$ işlemlerinde çalıştıkları tespit edilmiştir (Yılmaz ve ark., 2019).

İncelenen işletmelerle ilgili tüm kararlarda kadınların görüşüne başvurulmakla birlikte, teknik konulardaki kararlarda kadınlar daha az söz sahibidir. Kadınların karar almada, en etkili oldukları konu yetiştirilecek ürünlerin belirlenmesidir (3.24). Bunu; gübre kullanımı (2.84), hayvan satışı (2.84) ve hayvan satın almayla (2.80) ilgili kararlar takip etmektedir. Kadınların daha az etkili oldukları konular ise tarımsal eğitime katılma (2.09), kredi kullanımı (2.26) ve arazi kiralamayla (2.27) ilgili kararlardır (Tablo 4). İşletmelerde, fındık ve diğer bitkisel ürünler ile canlı hayvanların satışı konusunda genellikle erkekler söz sahibi iken, kadınlar süt ve mamullerinin pazarlanmasinda daha etkilidir. Alkan (2015) tarafından araştırma bölgesinde yapılan bir araştırmada, kadınların sadece $\%$ 25.45'inin tarımsal üretim faaliyetleri ile aletmakine satın almayla ilgili kararlara dâhil oldukları tespit edilmiştir. Aynı araştırmaya göre, kadınların \% 72.73'ünün hayvan satın almada, \% 36.36'sının ise çalıştırılacak işçilerle ilgili kararlarda 
Tablo 3. Fındık yetiştiriciliğinde işgücü kullanımı

\begin{tabular}{lcrrrrr}
\hline & \multicolumn{2}{c}{ Kadın } & \multicolumn{2}{c}{ Erkek $^{\text {Toplam }}$} \\
\cline { 2 - 7 } & EIGS da $^{-1}$ & $\%$ & EİGS da $^{-1}$ & \multicolumn{1}{c}{$\%$} & EIGS da $^{-1}$ & \multicolumn{1}{c}{$\%$} \\
\hline Budama & 0.58 & 7.68 & 6.97 & 92.32 & 7.55 & 13.13 \\
Gübreleme & 0.75 & 30.00 & 1.75 & 70.00 & 2.50 & 4.35 \\
İlaçlama & 0.17 & 8.06 & 1.94 & 91.94 & 2.11 & 3.67 \\
Dip sürgünü temizliği & 3.34 & 34.97 & 6.21 & 65.03 & 9.55 & 16.61 \\
Yabanc1 ot temizliği & 0.78 & 8.53 & 8.36 & 91.47 & 9.14 & 15.90 \\
Hasat & 14.98 & 62.11 & 9.14 & 37.89 & 24.12 & 41.95 \\
Patoza verme & 0.32 & 45.71 & 0.38 & 54.29 & 0.70 & 1.22 \\
Taş1ma & 0.18 & 9.89 & 1.64 & 90.11 & 1.82 & 3.17 \\
\hline Toplam & 21.10 & 36.70 & 36.39 & 63.30 & 57.49 & 100.00 \\
\hline
\end{tabular}

Tablo 4. Kadınların işletme kararlarına etkisi

\begin{tabular}{|c|c|c|c|c|c|c|}
\hline & $\begin{array}{c}\text { Hiçbir zaman } \\
(\%)\end{array}$ & $\begin{array}{c}\text { Nadiren } \\
(\%)\end{array}$ & $\begin{array}{c}\text { Ara sira } \\
(\%)\end{array}$ & $\begin{array}{c}\text { Genellikle } \\
(\%)\end{array}$ & $\begin{array}{c}\text { Her zaman } \\
(\%)\end{array}$ & Ortalama* \\
\hline Yetiştirilecek ürün & 19.44 & 8.34 & 22.22 & 27.78 & 22.22 & 3.24 \\
\hline Gübre kullanımı & 31.94 & 12.50 & 18.06 & 18.06 & 19.44 & 2.84 \\
\hline Hayvan satışı & 38.88 & 5.56 & 13.89 & 18.06 & 23.61 & 2.84 \\
\hline Hayvan satın alma & 38.88 & 5.56 & 15.28 & 18.06 & 22.22 & 2.80 \\
\hline Arazi satın alma & 34.73 & 11.11 & 19.44 & 15.28 & 19.44 & 2.73 \\
\hline Yabancı işçi çalıştırma & 36.11 & 8.34 & 22.22 & 20.83 & 12.50 & 2.65 \\
\hline Tarımsal ilaç kullanımı & 40.28 & 8.34 & 20.83 & 19.44 & 11.11 & 2.50 \\
\hline Alet-makine satın alma & 41.67 & 11.11 & 19.44 & 22.22 & 5.56 & 2.39 \\
\hline Findık satış1 & 45.83 & 8.34 & 18.06 & 19.44 & 8.33 & 2.37 \\
\hline Arazi kiralama & 54.16 & 5.56 & 12.50 & 12.50 & 15.28 & 2.27 \\
\hline Kredi kullanımı & 52.78 & 5.56 & 12.50 & 22.22 & 6.94 & 2.26 \\
\hline Tarımsal eğitime katılma & 51.39 & 6.94 & 25.00 & 11.11 & 5.56 & 2.09 \\
\hline
\end{tabular}

*: Sorulara verilen cevapların (hiçbir zaman:1, nadiren: 2, ara sıra: 3, genellikle: 4, her zaman: 5) ortalamasını ifade etmektedir.

görüşlerine başvurulmaktadır. Erzurum, Erzincan ve Bayburt illerinin kırsal alanlarında yapılan bir araştırmada, üretilen sebzelerin çoğunlukla erkekler tarafından pazarlandığ 1 ve sadece işletme yöneticisi konumundaki kadınların pazarlamada etkili oldukları tespit edilmiştir (Kaya ve Atsan, 2012). Tekirdağ ilinin kırsal alanında yapılan bir araştırmada da, ekonomik ve sosyal konularla ilgili kararlarda genel olarak erkeklerin etkili olduğu, kadınların ise giyim eşyalarının satın alınmasıyla ilgili kararlara daha fazla katıldıkları ortaya konulmuştur. Ayrıca hızla değişen dünya koşulları içerisinde kentleşme, ulaşım, sağlık, eğitim, göç ve teknolojideki gelişmelere rağmen kadınların aile içi ve dışı ilişkilerinde, üretim süreçlerindeki rollerinde ve kararlara katılımlarında olumlu bir gelişmenin olmadığ 1 ifade edilmiştir (Yılmaz ve ark., 2019).

\section{Sonuç ve Öneriler}

İncelenen işletmelerdeki ekonomik gücün büyük ölçüde findıktan elde edilen gelire bağlı olduğu söylenebilir. İşletmelerde kadınlar ağırlıklı olarak fındık hasadında çalışırken, erkekler daha çok budama, ilaçlama, yabancı ot temizliği ve taşıma gibi teknik işlerde yer almaktadır. Yoğun işgücü gerektiren fındık hasadında çalışan kadınlar, kredi kullanımı ve ürünlerin satışı gibi parasal konular, makine kullanımını gerektiren işler ve tarımsal eğitim faaliyetlerinde büyük ölçüde erkeklerin gerisinde kalmaktadır. Aynı şekilde kadınların eğitim gördükleri süre de erkeklerden oldukça düşüktür. Eğitim düzeyinin düşük olmas1, kadınların işletmedeki karar süreçlerine katılımını engelleyen önemli bir faktördür. Kırsal alandaki kadınlarda okullaşma oranının yükseltilmesi, ülkenin genel eğitim politikasıyla ilgili olmakla birlikte, bölgesel ve il düzeyinde uygulanacak tarımsal yayım faaliyetleriyle, kadınların ekonomik ve sosyal hayatın gerektirdiği tüm alanlardaki bilinçlenme düzeyleri artırılmalıdır.

İşletmelerde kadınlar genel olarak karar veren değil, verilen kararları uygulayan kişi konumundadır. Bu amaçla kadınların aile yönetimi ve tarımsal faaliyetlerde daha çok söz sahibi olmalarına yönelik uygulamalar artırılmalıdır. Fındık yetiştiriciliği yapan işletmelerdeki kadınlara yönelik öncelikli hedef, girişimci ve üretici olarak rol alacak kadınları uygun yayım yöntemleriyle eğitmek, kadınlara yeni teknolojileri kullanma kabiliyeti kazandırmak, uygulanabilir projelerin hayata geçirilmesiyle ilgili kadınlara yönelik etkinlikleri artırmak ve kadın girişimciliğini üst seviyeye çıkarmak olmalıdır. Kadınların tarımsal üretimdeki aktif rolleriyle birlikte, karar süreçlerindeki etkinliğinin de artırılması, tarımın kadınlar tarafindan bir meslek olarak kabul 
edilmesinde etkili olacaktır. İşletmelerde kadınların emeklerinin karşılığını almaları, ekonomik bağımsızlıklarını kazanmalarıyla birlikte, sosyal anlamdaki gelişimlerine de katkı sağlayacaktır. Çocukların doğru davranış biçimi edinmelerinde ailede etkin olan kadınların, sosyal yönden gelişmeleri kendileri için olduğu kadar yetiştirecekleri çocuklar açısında da büyük önem taşımaktadır.

Kadınlara üretimin her aşamasındaki kararlara katılma bilinci ve iletişim teknolojilerinden yararlanma bilgisinin verilmesi, kadının kırsal alandaki etkisini artıracaktır. Kadınların karar verme sürecine katılmaları için, kapasitelerini geliştirmeleri ve verdikleri kararları uygulama yetkinliğine sahip olmaları gerekir. Bun nedenle kırsal alandaki kadınların güçlendirilmesinde; kişisel gelişim, tarımsal eğitim, kaynaklara erişim, katılımcılık, cinsiyet eşitsizliğinin giderilmesi ve kadınların kalkınma sürecinde aktif rol almaları önemli faktörler olarak ele alınmalıdır. Bütün bu konuları içeren kırsal kalkınma çalışmaları, her şeyden önce kırsal alandaki kadınlara sürdürülebilir istihdam olanakları sağlamayı hedeflemelidir. Tarım işletmelerindeki kadınların istihdam alanları, sadece bitkisel ve hayvansal üretimle sınırlı olmamalı, bunun yanı sıra yöresel olanaklar göz önünde bulundurularak, köy el sanatları ve kırsal turizm gibi faaliyetlerle zenginleştirilmelidir. Kırsal alanda sürdürülebilir bir gelir elde eden kadınlar, aynı zamanda aile içindeki statüleri de yükseleceği için, üretimle ilgili kararlara daha aktif bir şekilde katılacaklardır.

\section{Kaynaklar}

Alkan, H.I., 2015. Tarım sektöründe kadın emeği (Çarşamba Ovası Gündoğdu ve Damlataş Köylerinde Fındık, Çeltik ve Sebze Üretimi özelinde bir irdeleme). Doktora tezi, Gazi Üniversitesi Sosyal Bilimler Enstitüsü, Ankara.

Anonim, 2018. İşgücü İstatistikleri. Türkiye İstatistik Kurumu, (http://www.tuik.gov.tr/PreHaberBultenleri .do?id=27693), (Erişim tarihi: 13.05.2020).

Anonim, 2019. Bitkisel Üretim İstatistikleri. Türkiye İstatistik Kurumu, (https://biruni.tuik.gov.tr/medas/? $\mathrm{kn}=92 \&$ locale=tr), (Erişim tarihi: 13.05.2020).

Anonymous, 2014. USDA Foreign Agricultural Service, Gain Report, Turkey Tree Nuts Annual. (https://apps.fas.usda.gov/newgainapi/api/report/dow nloadreportbyfilename? filename $=$ Tree $\% 20$ Nuts $\% 20$
Annual_Ankara_Turkey_10-16-2014.pdf), (Erişim tarihi: 13.05 .2020$)$.

Bayoğlu, A.S., 2010. Kırsal alanda kadının ekonomik konularla ilgili karar verme sürecine katılımı: Polatlı örneği. Gazi Üniversitesi Endüstriyel Sanatlar Eğitim Fakültesi Dergisi, 26: 57-65.

Berber, M., Eser, B.Y., 2008. Türkiye'de kadın istihdamı: Ülke ve bölge düzeyinde sektörel analiz. İs, Gü̧̧ Endüstri İlişkileri ve İnsan Kaynakları Dergisi, 10(2): 1-16.

Cinemre, H.A., Kılıç, O., 2015. Tarım Ekonomisi. Ondokuz Mayıs Üniversitesi, Ziraat Fakültesi, Ders Kitab1 No: 11, 5. Bask1, Samsun.

Erkuş, A., Demirci, R., 1985. Tarımsal İşletmecilik ve Planlama. Ankara Üniversitesi Ziraat Fakültesi Yayınları, Ankara.

Kaya, T.E., Atsan, T., 2012. Kırsal kadınların sosyoekonomik durumları ve geleceğe yönelik beklentileri (TRA1 Bölgesi örneği). Tartm Ekonomisi Dergisi, 18(1): 1-11.

Kaya, N., 2017. Kırsal ve kentsel alanda yaşayan evli kadınların evlilik uyumu, evlilik doyumu ve ilişkilerde mutluluk düzeylerinin karşılaştırılması ve incelenmesi. Yüksek lisans tezi, İstanbul Ticaret Üniversitesi Sosyal Bilimler Enstitüsü, İstanbul.

Kızılaslan, N., Yamanoğlu, A., 2010. Kırsal alanda kadınların tarımsal üretime ve aile içi kararlara katılımı: Tokat ili örneği. Uluslararası Sosyal Araştırmalar Dergisi, 3(13): 154-166.

Kutlar, İ., Kızılay, H., Turhanoğulları, Z., 2013. Kırsal alanda kadınların işgücüne ve kararlara katılımını etkileyen sosyoekonomik faktörlerin belirlenmesi: Burdur ili örneği. Akdeniz Üniversitesi Ziraat Fakültesi Dergisi, 26(1): 27-32.

Özer, M., Biçerli, K., 2003. Türkiye'de kadın işgücünün panel veri analizi. Anadolu Üniversitesi Sosyal Bilimler Dergisi, 3(1): 55-86.

Palaz, S., Boz, İ., 2007. Türkiye'de kırsal bölgede yaşayan kadınların demografik özellikleri, aile içindeki statüleri ve gelecek beklentileri: Balıkesir, Kayseri ve Kahramanmaraş illeri örneği. Yönetim ve Ekonomi Araştırmaları Dergisi, 5(7): 17-29.

Yamane, T., 1967. Elemantary Sampling Theory. Printice Hall Inc. Englewood Cliffs, Nt.

Yılmaz, Z., Ersin, F., 2019. Kadına Karşı Aile İçi Siddet. Şanlıurfa İli Kırsalı Kadın Profili Demografik, Sosyo-Ekonomik ve İstihdam Perspektifli Bir Araştırma. Ekin Yayınevi, Ankara.

Yılmaz, E., Özdemir, G., Oraman, Y., Unakıtan, G., Konyalı, S., 2019. Tarımsal üretimde kadınların karar alma süreçlerine katılımı ve kooperatiflerden beklentileri. Tekirda ̆ Ziraat Fakültesi Dergisi, 16(1): 71-81. 